\title{
A Comparison of students' attitudes and attainment on an enterprise module for scientists and engineers
}

\section{Robert A. Phillips}

Manchester Enterprise Centre, Alliance Manchester Business School, University of Manchester, Manchester, U.K.

\begin{abstract}
We compared data from an enterprise course aimed at scientists and engineers using the Unit Evaluation Questionnaire, coursework marks and qualitative feedback quotes with the aim of identifying any issues for embedding enterprise and entrepreneurship units in science and engineering degrees. Enterprise courses in many universities are often offered as units within other degree programmes which fulfill chartered bodies requirements for enterprise education and for employability. Whilst broadly accepted to be successful, others have reported students views on enterprise education be mixed as they feel its out of their comfort zone, and some are not open to studying units outside of their main subject, however we found student results and satisfaction to be at least as good as faculty and departmental norms. Qualitative comments suggest despite initial misgivings, they enjoy applying their subject knowledge to entrepreneurial issues and appreciate it not being a generic course. Students were not adversely affected by different assessment techniques and performed similarly to departmental/faculty averages. We found that it was key for courses to be tailored to science and engineering students such as by allowing them to study a company from their subject area for their assignments and giving science examples resulted in better engagement and feedback.
\end{abstract}

Keywords: Enterprise and Entrepreneurship Education; Science and Engineering Assessment; Interdisciplinary Teaching. 


\section{Introduction}

Many studies have shown that enterprise education is beneficial for science and engineering students (e.g. Souitaris et al., 2007; Maresch et al., 2016) not just in the context of starting their own business or commercializing research, but also as part of an employability focus with those having participated being seen as more employable by employers (O'Leary, 2012 and 2017). The Quality Assurance Agency for Higher Education in the UK (QAA, 2018) suggests all students should have some enterprise education as part of their overall development. Embedding enterprise in the curriculum for these students has been discussed (e.g. Clements, 2011; Handscombe et al., 2008). Tradeoffs exist between efficiency issues whether to use subject specific content for small groups of individual subject areas or use more generic courses with larger classes with the opportunity to mix with students from different backgrounds and subject areas, but where content is less tailored to subject areas. There are also a variety of activities on offer extracurricular at Universities (Papadopoulou, and Phillips, 2019 and Phillips, 2010), but some faculties and schools have decided that compulsory enterprise training is required for all students as part of their degree programmes which aligns with chartered body recommendations for degree courses.

Enterprise Education is useful for preparing students for an uncertain job market and producing high growth technology firms. Researchers also have found that Enterprise Education leads to higher Entrepreneurial Intention which is a good predictor of starting a business (Kautonen 2015, Martin et al 2013). Maresch (2016) found that Entrepreneurial Intention was raised more in business students than science and engineering suggesting this was because students who already have some business education are more likely to absorb entrepreneurship skills and knowledge. Further, it is suggested that science and engineering students can develop a social identity which rejects entrepreneurship in favour of pure science (Jungert 2013). However, it was found that an approach keeping the subject area (science and engineering) at the core of the teaching was a successful strategy for engaging students and reducing the construction of a negative social identity, in fact one study found that Entrepreneurial Intention was especially raised in electrical engineers (Duval-Couetil et al., 2012) and another in Spanish engineering students (Barba-Sánchez and Atienza-Sahuquillo, 2018). Our strategy was to use many science and engineering examples and encompass product development into the taught material and assessment, and with an applied assessment rather than an exam.

We consider a final year undergraduate enterprise course adapted for a range of science and engineering students. The course was of twelve two hour sessions, consisting of opportunity spotting and value creation, market research, basics of finance, risk management, cost control, sources of funding and growing a business. It is intended as a 10 credit unit within other subject areas (science and engineering), to address the need for graduates to be enterprising whether they start a business themselves or work in a larger organization. This 
course was made compulsory for many students based on feedback from employers and experts from the Chartered Bodies that accredit each degree programme, with employers complaining of students not able to apply their knowledge immediately and requiring training which is expensive for companies to provide. Since only about $5 \%$ of students will become self-employed on graduation, courses need to be relevant for those going to work for a wide range of organisations. These units fit well with employer and alumni needs and suggestions, but short term, lecturers need to get good feedback from students and often compulsory courses outside of the main subject area get poor feedback if students cannot see the relevance and they feel it is out of their comfort zone. This problem can arise with lecturers needing good feedback, rather than maybe teaching what is needed, or not teaching for the audience but simply transposing business school courses onto science students. In terms of summative assessment, often enterprise courses have a more practical element of assessment such as reflective journals (Phillips, 2008), posters, feasibility reports, business plans, or pitch presentations. They also can involve group working and Enquiry Based Learning (SanchezRomaguera and Phillips, 2018). Alumni entrepreneurs have said that the more practical the courses and the assessment, the more valuable for those planning to start a business (Phillips, 2018).

For many of the students, the assessment for the unit was different to what they were used to which was primarily examination and lab work. It consisted of a 4000 word assignment whereby the student analysed the current state of a company from their own subject area using financial measures and suggested a ways the company could add further value to the company's products or services based on market research and with costing. This was part of "dealing with uncertainty", an important learning outcome of an enterprise course which students can be uncomfortable with, especially students from a subject area where a defined numerical answer is the norm. Using real data from databases, speaking to customers or companies gave a more practical and applied assignment which was hoped would appeal to students. There were also two "consultancy" sessions where students could meet with the lecturer and ask specific questions and discuss their assignment, it was hoped this would alleviate any issues students might have with the assignment by providing reassuring guidance. An important issue is not just whether entrepreneurial intention is raised, but whether students are able to adapt to the demands of different assessments and the aim of this paper is to understand any issues there might be in improving the offering so not only are outcomes achieved but students feel confident in taking entrepreneurship courses and also give good feedback which is important to teaching staff.

\section{Methodology}

We compared students from science and engineering subject areas in four separate classes computer science, electrical engineering, and two mixed class (chemical engineering, 
mechanical engineering and biotechnology) and looked at data over a three year period from each of these classes. We used feedback from the Unit Evaluation Questionnaire from each area (filled in anonymously and electronically at the end of the course), student assignment marks and comparing with school averages where possible. We also investigated qualitative comments to further understand any issue that students felt were important for this type of course. This data collected was also anonymous giving students a chance to freely reflect their views. Class sizes ranged from 37-76 students and data was collected from the years 2016/17, 2017/18 and 2018/19. For most classes, the sessions were 2 hours per week for 12 weeks but for electrical engineers sessions they were three weeks of 4 hours per week, a three week break then a further three weeks of 4 hours per week, although no comments were made by students about lecture scheduling.

\section{Results and Discussion}

From the qualitative comments, it is clear that the students initially had similar fears to those found by other researchers that the method of assessment was different to what they were used to, and as final year students, were worried that this might impact their marks with students commenting -

"A 100\% coursework module is very heavy, and whilst support was given from the lecturer, formal instructions and advice given about the subject at the beginning was quite brief, can be open to discussion a lot which is very risky, especially if a full 3rd year module depends on it"

"And could provide a guide as to how to do the assessment, what is expected of this type of work as most people have never done a piece of work to this level before."

We also found the phenomena that some students didn't see the relevance of doing this type of course within their degrees and there was a worry that students would revert to social norms within their subject area and reject anything new, or new ways of learning -

"I believe for some it may have been difficult to understand why we were taking this unit and what relation it has to our degree, although this may be at the discretion of the School of EEE"

Some didn't understand the need to apply the knowledge learned e.g. "why are we looking at $X$ when the assignment is about $Y$ " when learning how to apply models in different situations.

The marks achieved by the students seem to show however that they performed well in the assignment (Table 1) and marks were at least as good as those achieved in other units. Table 1 also shows that there is little difference between the marks obtained by students on the separate courses from Computer Science, Electrical Engineering, and mixed classes of Chemical Engineering and Biotechnology. 
Table 1: Average marks (\%) and number of students on each course (in brackets)

\begin{tabular}{cccc}
\hline Subject Area & $\mathbf{2 0 1 8 - 1 9}$ & $\mathbf{2 0 1 7 - 1 8}$ & $\mathbf{2 0 1 6 - 1 7}$ \\
\hline Computer Science (Semester Two) & $67.04(47)$ & $66.18(64)$ & $66.17(67)$ \\
Engineering/Biotechnology (Semester One) & $70.79(56)$ & $69.69(42)$ & $66.63(44)$ \\
Engineering/Biotechnology (Semester Two) & $69.69(55)$ & $69.41(37)$ & $66.35(40)$ \\
Electronic Engineering (Semester One) & $71.81(60)$ & $68.62(76)$ & $68.61(76)$ \\
\hline
\end{tabular}

Data obtained from the Unit Evaluation Questionnaire survey at the end of the course shows above average feedback from students compared to departmental and faculty norms (Table 2). Feedback, in terms of satisfaction, was high from all classes and similar to departmental norms. Fears that science students would revert to social identity where anything different was rejected seemed unfounded. Others within the university have found that with compulsory units where students feel they are forced to do something they are not interested in some students give negative feedback automatically, however the feedback for all courses is above school and faculty average, suggesting students were happy with the course. We found also that there were no individual students that gave significant negative feedback.

Table 2: Data shows student feedback data (marked out of 5) for each course, brackets are school average scores

\begin{tabular}{cccc}
\hline Subject Area & $\mathbf{2 0 1 8 - 1 9}$ & $\mathbf{2 0 1 7 - 1 8}$ & $\mathbf{2 0 1 6 - 1 7}$ \\
\hline Computer Science (Semester Two) & $4.33(4.16)$ & $3.80(4.09)$ & $4.29(4.06)$ \\
Engineering/Biotechnology (Semester One) & $3.93(4.16)$ & $4.80(4.09)$ & $4.00(4.06)$ \\
Engineering/Biotechnology (Semester Two) & $4.40(4.16)$ & $3.93(4.09)$ & $4.25(4.06)$ \\
Electronic Engineering (Semester One) & $4.17(4.16)$ & $3.82(4.09)$ & $4.20(4.06)$ \\
\hline
\end{tabular}

Qualitative comments suggest that many students in fact valued the course in terms of it being applicable to industry and were challenged positively by the different methods of assessment. Many more students commented on the usefulness of the course and appeared to understand the reasoning behind the course and what they would take away from the unit;

"This assignment was challenging, it required having to do quite a few things I was unsure about e.g. finding the probability of a risk, what product change to choose (the cost of this, the sales of this), however due to the great feedback it was achievable and a lot simpler than I was making it for myself. Despite it being challenging, I am now really glad I did this module, as it involved a lot of analyses which I feel will come in use later on in my work 
career. This module was good because it also helped me think about what I might like to do after university. Overall, I'm really happy with this module"

"A content that will actually be useful for the future. An assessment that has meaning and is enjoyable. The independence of the coursework task"

"Real world examples a good level for non- business students"

"I really enjoyed how feasible and practical the module was. -Has a good mixture between theory and practice where we can use our knowledge of the theory learned in class into our assignments"

"The assignments were fun, and different to anything I've done before"

It was observed anecdotally that in each year Computer Science students had a much lower attendance than other groups, and made less use of the consultancy sessions, but those that engaged were very engaged - attending every session and consultancy, with many emails and discussions after the lectures. Some students however attended no lectures, it was found to be normal in Computer Science that some students didn't attend lectures. The computer science average results seemed slightly lower overall - although there was a broader spread of marks with some very high and very low marks. Survey showed that many computer science students prefer to work off podcasts rather than attend lectures (voice and slides podcast were available for all lectures).

\section{Conclusions / Discussion}

Despite initial worries from some students, that they were doing something new - that they hadn't written a report before, and often referred to the coursework as an "essay", marks were comparable to other units they were doing elsewhere. It seems that the students adapted quickly to different forms of assessment. Many students particularly valued the individual meetings and consultancy to get help on the coursework which helped bridge the gap. The students who filled in the UEQ seemed happy with the course and the teaching, despite it being compulsory for some. The feedback was similar or above the school average in most cases. Key to gaining acceptance from students seems to be to explain and show how enterprise applied to their subject, give examples from their subject area to show relevance early on. Allowing the assignment to be on a company of their choice in their subject area was helpful - they feel like its aimed at them and gives them a chance to apply knowledge from their subject area. This compares with generic enterprise courses which often get lower feedback as students don't feel like it's aimed at them. It is important to reflect on feedback previously obtained from employers and alumni entrepreneurs who value the more practical approach and allow students working in industry to apply their knowledge to problems of commercial value as soon as they begin their careers rather than be stuck in an academic 
mindset which requires extensive training to allow them to make use of their subject knowledge. The study was limited by the numbers of students filling in the UEQ which tends to be about $50 \%$, so some student views are not accounted for. For further work, we plan to investigate any specific groups of students who might do well in their subject area, but poorly in enterprise to identify any particular issues. We also plan to look at arts and humanities subjects as well as science and engineering. Anecdotally, employers have said they like the course and more practical assessment but this could be followed up more formally by interviewing students after they have begun employment.

\section{References}

Barba-Sánchez, V., \& Atienza-Sahuquillo, C. (2018). Entrepreneurial intention among engineering students: The role of entrepreneurship education. European Research on Management and Business Economics, 24(1), pp.53-61.

Clements, M. (2011). Embedding enterprise in the university curriculum: Can one solution fit all?. Journal of Higher Education Theory and Practice, 11(3), pp.9-18.

Duval-Couetil, N., Reed-Rhoads, T., \& Haghighi, S. (2012). Engineering students and entrepreneurship education: Involvement, attitudes and outcomes. International Journal of Engineering Education, 28(2), pp.425.

Handscombe, R.D., Rodriguez-Falcon, E., \& Patterson, E. A. (2008). Embedding enterprise in science and engineering departments. Education+ Training, 50(7), pp.615-625.

Jungert, T. (2013) Social identities among engineering students and through their transition to work: a longitudinal study Studies in Higher Education, 38, pp. 39-52

Kautonen, T., van Gelderen, M. and Fink, M.(2015). Robustness of the theory of planned behaviour in predicting entrepreneurial intentions and action Entrepreneurship Theory and Practice, 39, pp. 655-674

Maresch, D., Harms, R., Kailer, N. and Wimmer-Wurm, B. (2016). The impact of entrepreneurship education on the entrepreneurial intention of students in science and engineering versus business studies university programs. Technological forecasting and social change, 104, pp.172-179.

Martin, B.C., McNally, J.J. and Kay M.J. (2013). Examining the formation of human capital in entrepreneurship: a meta-analysis of entrepreneurship education outcomes Journal of Business Venturing, 28, pp. 211-224.

O'Leary, S. (2017). Graduates' experiences of, and attitudes towards, the inclusion of employability-related support in undergraduate degree programmes; trends and variations by subject discipline and gender. Journal of Education and Work, 30(1), pp.84-105.

O'Leary, S. (2012). Impact of entrepreneurship teaching in higher education on the employability of scientists and engineers. Industry and Higher Education, 26(6), pp. 431442.

Papadopoulou, K.A. and Phillips, R.A. (2019). A comparison of on-curricular and offcurricular activities in enterprise education for postgraduate students. Proceedings of the 5th International Conference on Higher Education Advances (HEAd'19) pp. 55-64. 
Phillips, R. A. (2018). A Retrospective Study on the Views of Alumni Entrepreneurs Towards University Enterprise Education and Training IUP. Journal of Knowledge Management, 16(3), pp.54-71.

Phillips, R. A. (2010). Encouraging a more enterprising researcher: the implementation of an integrated training programme of enterprise for $\mathrm{Ph}$. D. and postdoctoral researchers, Research in Post-Compulsory Education, 15(3), pp.289-299.

Phillips, R.A. (2008). The Use of Personal Journals for Assessment of an Undergraduate Enterprise Module. Journal of Asia Entrepreneurship and Sustainability, 4 (4), pp.77-89.

Sanchez-Romaguera, V. and Phillips, R.A. (2018). A comparison of a first and final year UG enterprise unit: lessons from experiential learning and interdisciplinarity. Proceedings of the 4th International Conference on Higher Education Advances (HEA'd 2018) pp.899907.

Souitaris, V., Zerbinati, S., \& Al-Laham, A. (2007). Do entrepreneurship programmes raise entrepreneurial intention of science and engineering students? The effect of learning, inspiration and resources. Journal of Business venturing,22(4), pp.566-591.

QAA, Quality Assurance Agency for Higher Education (2018). Enterprise and entrepreneurship education guidance for UK higher education providers, available online at: http://www.qaa.ac.uk/en/Publications/Documents/Enterprise-andentrpreneurship-education-2018.pdf 